\title{
PERANCANGAN SISTEM KENDALI GERAK ROBOT BERODA MENGGUNAKAN XBEE PRO REMOTE
}

\author{
M Zulfitra $^{1}$, Pamor Gunoto ${ }^{2}$ \\ Teknik Elektro Fakultas Teknik Universitas Riau Kepulauan \\ Jln. Batu Aji Baru No.99, Kepulauan Riau Telepon: ( 0778 ) 392752 \\ pguonoto@yahoo.co.id, zulfitraunrika@yahoo.co.id.
}

\begin{abstract}
Abstrak
Sistem Robotika merupakan salah satu solusi untuk mempercepat pengerjaannya dan mempermudah proses produksi untuk mencapai hasil kapasitas maksimal, Robot adalah bentuk mekanis dan elektrik yang didesain sebagai penunjang agar mempermudah manusia melakukan pekerjaan, salah satu pengaplikasian robot terhadap pengerjaan pada proses produksi manufaktur adalah sebagai pengangkat atau pemindah barang, pengaplikasian ini dilakukan adalah untuk mengurangi resiko kecelakaan kerja terhadap operator, sehingga mengangkat dan memindahkan barang dilakukan oleh Robot. Sistem kontrol robot telah banyak teralisasi dengan menggunakan beberapa metode- metode kontrol, dari metode kontrol otomatis dan juga semi otomatis. pada penelitian ini merancang sistem kendali gerak robot dengan jenis kontrol semi otomatis yang telah diiplementasikan menggunakan sistem kendali jarak jauh yang memanfaatkan module xbee pro sabagai alat bantu komunikasi wireless, joystick sebagai penghasil data dan diolah menggunakan mikrokontrol arduino. Untuk dapat menerima data yang telah dikirim dirancang sebuah penerima wireless modul xbee pro receiver kemudian data tersebut dijadikan sebagai instruksi dalam mengontrol gerak robot. Dari hasil penelitian didapatkan bahwa xbee pro modul dapat digunakan mengontrol gerak robot dengan hasil data jarak kontrol maksimal 90 meter, ini membuktikan bahwa sistem kendali menggunakan wireless kotrol xbeepro berjalan dengan baik dan dapat mengontrol pergerakan sesuai dengan instruksi yang diberikan melalui joystick.
\end{abstract}

Kata kunci: joystick, remote, xbee pro modul, wireless.

\section{Pendahuluan}

Kota batam merupakan kota Industri, dimana Industri-Industri yang berada di Kota Batam adalah $40 \%$ bergerak di sektor manufaktur, $50 \%$ galangan kapal $10 \%$ di bidang mebel, dan selebihnya adalah industri rumah tangga. Dari beberapa sektor diatas dalam proses untuk mencapai hasil yang maksimal di tiap-tiap industri telah banyak melakukan perbaikan-perbaikan, sebagian besar perindustrian dibatam terutama industri manufaktur, melakukan terobosan yang berupa perbaikan sistem dilapangan yaitu dengan menjadikan Dunia Robotika sebagai penunjang untuk mencapai target yang sesuai dengan kapasitas permintaan dari customer.

kapasitas permintaan customer yang semakin meningkat, menyebabkan perusahaan harus berfikir melakukan perbaikan sehingga proses produksi dan hasil produksi mencapai sesuai dengan keinginan.

Sistem Robotika merupakan salah satu solusi untuk mempercepat pengerjaannya dan mempermudah proses produksi untuk mencapai hasil kapasitas maksimal, Robot adalah bentuk mekanis dan elektrik yang didesain sebagai penunjang agar mempermudah manusia melakukan pekerjaan, salah satu pengaplikasian robot terhadap pengerjaan pada proses produksi manufaktur adalah sebagai pengangkat atau pemindah barang, pengaplikasian ini dilakukan adalah untuk mengurangi resiko kecelakaan kerja terhadap operator, sehingga mengangkat dan memindahkan barang dilakukan oleh Robot.

Pengaplikasian Robot dibagi atas beberapa bagian yaitu Robot Automatis dan Semi Automatis, dimana Robot Automatis adalah Robot yang bergerak secara otomatis 
Sigma Teknika, Vol.1, No.2 : 133-143

November 2018

E-ISSN 2599-0616

P ISSN 2614-5979

tidak menunggu perintah external dan begitu sebaliknya Robot Semi Automatis yang mana Robot bergerak sesuai intruksi yang diberikan.

Berdasarkan fungsi dan pengaplikasian pengendalian dari Robot salah satuya Robot Semi Automatis dibagi atas dua yaitu Robot yang dikendaliakan masih dengan menggunakan kabel dan Robot yang dikendalikan tampa kabel.

Masih banyak terdapat dibeberapa industri Robot pemindah atau pengangkat barang menggunakan kontrol kabel, oleh karena itu peneliti merancang sebuah Robot yang dikontrol dengan tanpa kabel, penggerak Robot dikontrol dengan menggunakan tombol kontrol, akan tetapi komunikasi datanya dilakukan dengan tanpa kabel, sehingga judul dari penelitian ini adalah" Perancangan Sistem Kendali Gerak Robot Beroda Menggunakan Xbee Pro Remote"

\section{Perancangan Sistem}

Perancangan sistem pada penelitian ini dapat digambarkan dalam bentuk blok diagram seperti pada Gambar 3.1. Dimana terdiri dari 4 (empat)device utama yaitu Xbee receiver module sebagai input data, Arduino UNO yang digunakan untuk pengolahan data, Remote yang digunakan untuk kontrol pergerakan motor, dan motor DC yang digunakan untuk proses bergeraknya robot. Sensor Xbee receiver module disini berfungsi untuk mengirimkan informasi yang diolah pada Arduino UNO dan selanjutnya akan dikeluarkan melalui pergerakan motor DC. Hasil pengolahan informasi tersebut berupa data instruksi yang diberikan melalui remote kontrol.
Berikut adalah diagram blok sistem hardware pada perancangan skripsi ini.

Keterangan blok diagram pada Gambar 3.1 adalah sebagai berikut:



Gambar 3.1. Blok diagram sistem hardware
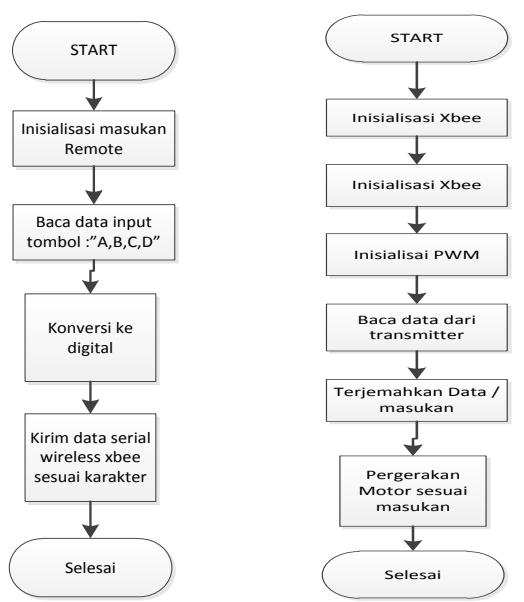

Gambar 3. Flowchart Pengiriman dan Penerimaan Data kontrol

\subsection{Perancangan program}

Berdasarkan perancangan alur kerja atau flowchart pada sub bab diatas dihasilkan sebuah algoritma program, dimana pada alat ini menggunakan satu bagian untuk pengontrol pergerakan robot yaitu wireless controller dan satu buah robot yang yang dikontrol pergerakannya.

A. Algoritma program pengontrol : 
Sigma Teknika, Vol.1, No.2 : 133-143

November 2018

E-ISSN 2599-0616

P ISSN 2614-5979

Bagian pengontrol atau wireless controller di rancang algoritma program dimana input data yang didapat dari pembacaan analog data dari potensio yang terdapat pada wireless controller dijadikan input dan hasil pembacaan data tersebut secara langsung dikirim secara serial melalui modul xbee transmitter. Data yang dikirim dengan format yaitu sebagai berikut:

Analog kiri atas

(data)

Analog kiri bawah : $\quad$ B

(data)

Analog kanan atas : $\quad$ C

(data)

Analog kana bawah $\quad$ : D (data)

Sehingga serial data terkirim : A (data)+ B (data)+ C (data)+ D (data)

Berikut perancangan dalam bentuk listing program yang deprogram menggunakan arduino software:

Serial.print("A");

Serial.println(outputValue);

Serial.print("B");

Serial.println(outputValue1);

Serial.print("C");

Serial.println(outputValue2);

Serial.print("D");

Serial.println(outputValue3);

B. Algoritma program robot:

Bagian robot dirancang program dimana input data diperoleh dari xbee pro receiver, data tersebut di inisialisasikan berdasarkan data yang dikirim dan data tersebut sebagai pemberi instruksi untuk membedakan pergerakan robot, adapun bentuk instruksi yang diterima berdasarkan format pengiriman maka data yang diterima diproses dengan instruksi sebagai berikut:
Jika terima data A maka motor kanan cw motor kiri diam, pwm=data

Jika terima data B maka motor kanan ccw motor kiri diam, pwm=data

Jika terima data $\mathrm{C}$ maka motor kiri cw motor kanan diam, pwm=data

Jika terima data D maka motor kiri ccw motor kanan diam, pwm=data

\subsection{Blok Diagram Sistem \\ keseluruhan}

Berikut adalah blok diagram

keseluruhan pada perancangan ini,

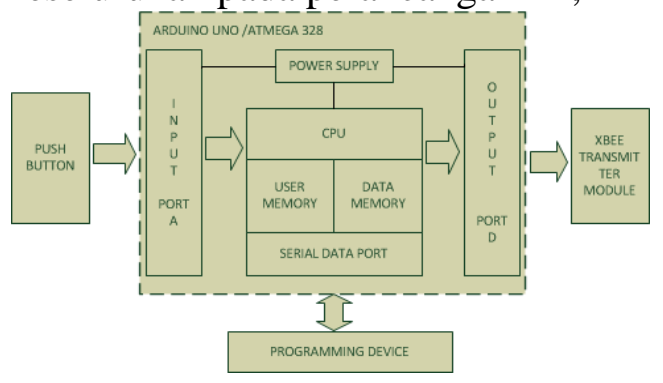

Gambar 3.2 Blok Diagram Untuk Transmitter

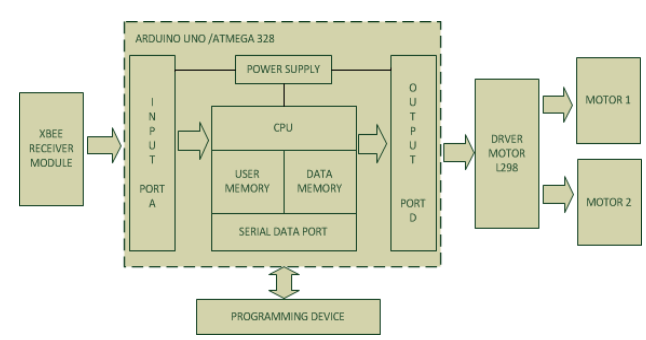

Gambar 3.3 Blok Diagram Untuk Receiver

Pada Gambar 3.2 dapat dilihat bahwa sistem kendali robot menggunakan xbee pro module ini terbagi menjadi 2 proses, yaitu proses pengiriman data yang dilakukan melalui joystic/remote dan proses penerimaan data yang data tersebut akan diolah untuk instruksi pergerakan robot. Kedua proses tersebut mempunyai tahapan yang 
sebagian besar sama, dimana tahapantahapan tersebut dimulai dari penentuan instruksi pada program untuk bagian pengiriman data. Data tersebut dikirim berdasarkan instruksi tombol yang ditekan.

Pada bagian penerima terdapat module xbee pro yang memproses data tersebut dan data tersebut dapat diakses secara serial, oleh karena itu setiap data yang diterima diindikasikan sebagai instruksi pemberi gerakan kepada Robot dan seterusnya data tersebut dipisahkan berdasarkan instruksi untuk menggerakkan motor sebagai aktuator robot .

Dari blok diagram dan penjelasan diatas perancangan alat dimulai dengan tahapan pengumpulan komponen-komponen yang diperlukan untuk pembuatan alat penelitian ini, adapun alat atau modul - modul yang di diperlukan sebagai berikut:

1. Xbee Receiver modul: sebagai modul komunikasi yang berfungsi sebagai penerima data secara wireless.

2. Xbee Tansmitter modul: sebagai modul komunikasi yang berfungsi sebagai pengirim data secara wireless.

3. Arduino Uno 1: sebagai mikrokontrol pemroses data input xbee receiver dan pengontrol dari output ke driver motor.

4. Arduino Uno 2: sebagai mikrokontrol pemroses data input xbee transmitter dan pengontrol dari wireless control atau remote..

5. Driver motor : sebagai modul yang mendrive motor

6. Power Supply / batre : sebagai suply tegangan ke setiap modul modul control.
Kemudian dilanjutkan dengan penggabungan setiap modul - modul yang telah dibuat menjadi satu bagian.

\section{Perancangan Perangkat Keras}

perancangan perangkat keras yang digunakan dalam robot wireless kontroler adalah yaitu sebagai berikut:

1. Mekanikal robot: body Robot

2. Unit Input : Remote dan Xbee transmitter, Xbee receiver

3. Unit Proses : Arduino 1( Transmitter ), Arduino 2( Receiver )

\section{Unit Output : Driver Motor DC}

\subsection{Mekanikal Robot}

Bodi robot dirancang dengan menggunakan bahan acrylic yang bertujuan sebagai peletakkan motor dan komponen. Bagian dudukan mempunyai ukuran $30 \mathrm{~cm}$ x $30 \mathrm{~cm} \mathrm{x}$ $30 \mathrm{~cm}$ (panjang $\mathrm{x}$ lebar $\mathrm{x}$ tinggi) yang digunakan untuk tempat dudukan motor, xbee receiver dan driver motor dan lain-lain. Sedangkan dudukan remote atau joytick mempunyai ukuran $10 \mathrm{~cm}$ x $15 \mathrm{~cm}$ x $30 \mathrm{~cm}$ (panjang $\mathrm{x}$ lebar $\mathrm{x}$ tinggi).
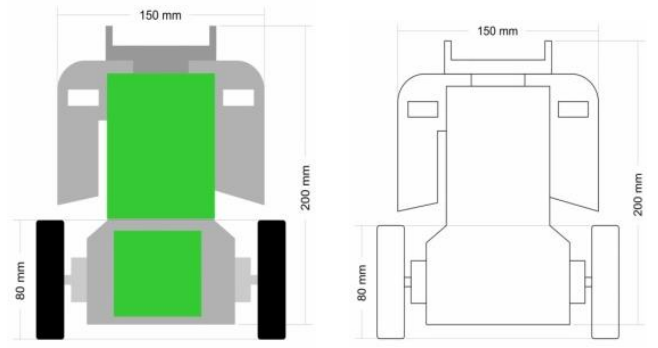

Gambar 3.6. Perancangan sistem mekanik robot 


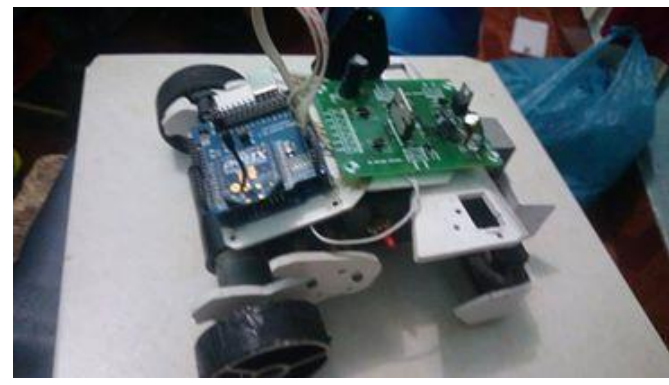

Gambar 3.6. Hasil Perancangan sistem mekanik robot

\subsection{Perancangan Elektronik}

Sistem yang telah dirancang dibagi atas dua bagian yaitu sistem pengontrol ( wireless controller) atau Transmitter dan sistem dikontrol (

\begin{tabular}{|c|c|}
\hline $\begin{array}{c}\text { PIN } \\
\text { Arduino2 }\end{array}$ & Hardware \\
\hline RX & $\begin{array}{c}\text { XBEE MODUL } \\
\text { RECEIVER }\end{array}$ \\
\hline TX & $\begin{array}{c}\text { XBEE MODUL } \\
\text { RECEIVER }\end{array}$ \\
\hline D4 & Direksi Driver Motor1 \\
\hline D5 & Direksi Driver Motor1 \\
\hline D6 & Direksi Driver Motor2 \\
\hline D7 & Direksi Driver Motor2 \\
\hline D9 & PWM Driver Motor2 \\
\hline D10 & PWM Driver Motor2 \\
\hline
\end{tabular}

robot ) atau receiver.

Perancangan sistem rangkaian transmitter dibagi menjadi beberapa bagian yaitu :

1. Input: berasal dari data analog potensiometer pada wireless controller /joystick.

2. Proses : mikrokontroller menggunakan Arduino Uno.

3. Ouput : xbee modul receiver

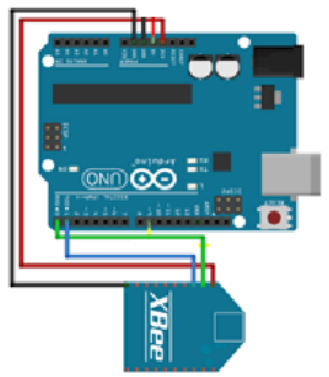

Gambar 4.2 Desain rangkaian wireless kontoller

Pin konfigurasi yang terhubung ke mikrokontrol sebagai berikut:

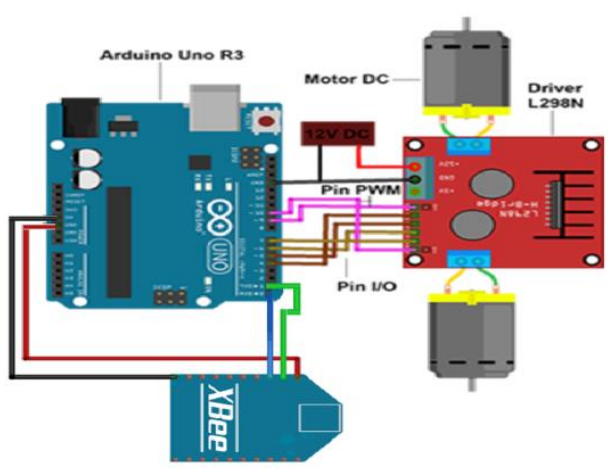

Gambar 4.2 Desain Rangkaian Robot Pin konfigurasi yang terhubung ke mikrokontrol sebagai berikut:

Tabel 4.1. Konfigurasi Pin

\section{Hasil Perancangan Alat}

Hasil perancangan alat pada peniltian ini merepresentasikan bentuk nyata atau reaslisasi bentuk yang telah terealisasi, dari bagian - bagian perancangan pada bab sebelumnya dihasilkan sebuah alat robot beroda dengan sistem menggunakan xbee pro remote, adapun bentuk yang terealisasi dibagi atas dua bagian yaitu bagian pengendali robot atau wireless kontroler dan robot beroda, adapun bentuk nya dapat dilihat pada gambar berikut:
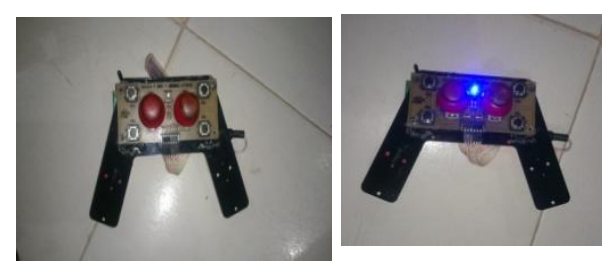

Gambar 5.1 xbee pro remote/wireless kontroler 
Sigma Teknika, Vol.1, No.2 : 133-143

November 2018

E-ISSN 2599-0616

P ISSN 2614-5979
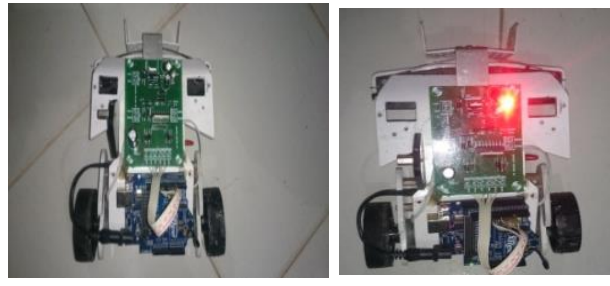

Gambar 5.2 Robot Beroda

\subsection{Pengumpulan Data}

Beberapa data telah berhasil dikumpulkan berdasarkan hasil pengetesan dan pengujian terhadap robot kontrol wireless ini, berikut ini adalah data - data yang telah dikumpulkan:

1. Pengujian Driver Motor DC : Pengujian pengukuran driver motor dc meliputi direksi atau arah putaran motor dc dan pengukuran tegangan kerja driver motor dc. pengujian arah putaran dengan memberikan instruksi dari program kontrol arduino sedangkan pengukuran tegangan kerja driver motor dc diakalukan dengan mengukur langsung output yang keluar dari driver motor dc.

2. Pengujian dan Pengukuran sinyal output xbee transmitter: pengujian dilakukan dengan memberikan instruksi melalui wireless control / transmitter dan hasil diukur melalui output / TX pin yang terukur pada xbee transmitter modul.

3. Pengujian dan Pengukuran sinyal output xbee receiver: pengujian dilakukan dengan memberikan instruksi melalui wireless control / transmitter dan hasil diukur melalui output / RX pin yang terukur pada xbee receiver modul.

4. Pengujian Respon Robot Terhadap Pengontrollan Menggunakan Remote

5. Pengujian jarak kontrol: pengujian dilakukan berdasarkan pengujian kontrol robot melalui wireless kontroller dan jarak control diukur menggunakan meteran.

\subsection{Pengumpulan Data}

Beberapa data telah berhasil dikumpulkan berdasarkan hasil pengetesan dan pengujian terhadap robot kontrol wireless ini, berikut ini adalah data - data yang telah dikumpulkan:

1. Pengujian Driver Motor DC : Pengujian pengukuran driver motor dc meliputi direksi atau arah putaran motor dc dan pengukuran tegangan kerja driver motor dc. pengujian arah putaran dengan memberikan instruksi dari program kontrol arduino sedangkan pengukuran tegangan kerja driver motor dc diakalukan dengan mengukur langsung output yang keluar dari driver motor dc.

2. Pengujian dan Pengukuran sinyal output xbee transmitter: pengujian dilakukan dengan memberikan instruksi melalui wireless control / transmitter dan hasil diukur melalui output / TX pin yang terukur pada xbee transmitter modul.

3. Pengujian dan Pengukuran sinyal output xbee receiver: pengujian dilakukan dengan memberikan instruksi melalui wireless control / transmitter dan hasil diukur melalui output / RX pin yang terukur pada xbee receiver modul.

4. Pengujian Respon Robot Terhadap Pengontrollan Menggunakan Remote

5. Pengujian jarak kontrol: pengujian dilakukan berdasarkan pengujian kontrol robot melalui wireless kontroller dan jarak control diukur menggunakan meteran.

\subsubsection{Pengujian Motor DC}


Pengujian ini dilakukan untuk mengetahui bahwa driver motor bekerja dengan baik sehingga dapat menjalankan motor DC.

Adapun peralatan yang di butuhkan dalam pengujian driver motor sebagai berikut:

1) Arduino UNO ATmega 328

2) 2(dua) unit rangkaian driver motor DC

3) Multi meter digital

4) 2 (dua) unit motor DC

5) Power supply

Untuk blok diagram pengujian driver motor DC ini dapat dilihat pada gambar

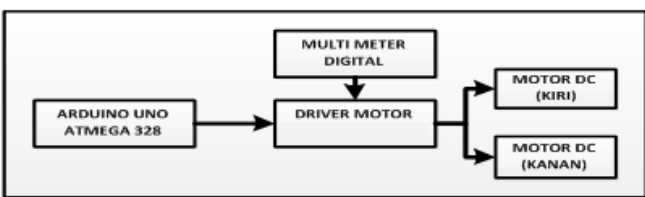

Gambar 5.3 Diagram Blok Pengujian DriverMotor DC

Untuk pengujian drivermotor DC diperlukan beberapa persiapan sebagai berikut:

1) Mengetik program pengujian driver motor DC

2) Menjalankan program pengujian

3) Membandingkan antara program uji yang telah di-download dengan reaksi motor DC dengan pengukuran tegangan dan kecepatan motor secara visual.

Pengujian driver motor ini dilakukan untuk mengetahui respon dan juga karakter dari driver. Input driver terdiri dari direksi sebagai penentu arah putaran motor dan PWM

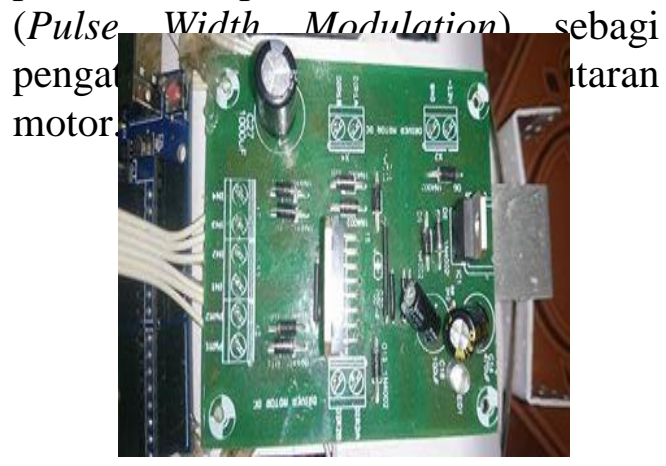

\section{Gambar 5.4 Driver motor DC}

Gambar 3.8 merupakan driver motor yang terkoneksi langsung ke mikrokontroller. Untuk menguji karakter dari driver motor diatas langkah awal yaitu dengan menguji Direction untuk menetukan arah putaran, hasil dari pengujian direction dapat dilihat pada Tabel 5.1.

Tabel 5.1 Hasil Pengujian Direction driver motor

\begin{tabular}{|c|c|c|c|c|c|c|}
\hline \multicolumn{6}{|c|}{ INPUT } & \multirow{3}{*}{ REAKSI } \\
\hline DIR_ & DIR_ & DIR_ & DIR_ & PWM & PWM & \\
\hline MIA & МІв & $\mathrm{M} 2 \mathrm{~A}^{-}$ & M2B & MI & M2 & \\
\hline 1 & 0 & 1 & 0 & 255 & 255 & Maju \\
\hline 0 & 1 & 0 & 1 & 255 & 255 & Mundur. \\
\hline 0 & 0 & 1 & 0 & 0 & 255 & Belok kiri \\
\hline 1 & 0 & 0 & 0 & 255 & 0 & Belok kanan \\
\hline 0 & 1 & 1 & 0 & 0 & 255 & Manuver kiri \\
\hline 1 & 0 & 0 & 1 & 255 & 0 & Manuver kanan. \\
\hline 1 & 1 & 1 & 1 & 0 & 0 & diam \\
\hline 0 & 0 & 0 & 0 & 0 & 0 & diam \\
\hline
\end{tabular}

Berikut pemrograman yang telah berhasil terealisasi berdasarkan tabel diatas untuk menguji arah putaran motor, sebagai berikut:

digitalWrite(DO_Dir1a, LOW); //

Pin Driver motor 1A digitalWrite(DO_Dir1b, HIGH); //

Pin Driver motor 1B digitalWrite(DO_Dir2a, LOW); //

Pin Driver motor 2A digitalWrite(DO_Dir2b, HIGH); // Pin Driver motor 2B analogWrite(DO_Pwm1, 255); // PWM Kontrol motor 1 analogWrite(DO_Pwm2, 255); // PWM Kontro motor 2

Pengendalian motor tidak terlepas dari pengendalian kecepatan, kendali 
kecepatan motor dc dapat dilakukan dengan mengunakan pengontrolan melalui mikrokontroler dengan metode PWM dari hasil pengendalian PWM

Tabel 5.2 Hasil Pengujian Kecepatan Motor DC

\begin{tabular}{|c|c|c|}
\hline NO & Data PWM (Dec) & Tegangan motor(volt) \\
\hline 1 & 0 & 0 \\
\hline 2 & 50 & 5.01 \\
\hline 3 & 60 & 8.16 \\
\hline 4 & 70 & 9.8 \\
\hline 5 & 80 & 10.22 \\
\hline 6 & 90 & 10.47 \\
\hline 7 & 100 & 10.61 \\
\hline 8 & 110 & 10.76 \\
\hline 9 & 120 & 10.95 \\
\hline 10 & 130 & 11.05 \\
\hline 11 & 140 & 11.16 \\
\hline 12 & 150 & 11.25 \\
\hline 13 & 160 & 11.31 \\
\hline 14 & 170 & 11.37 \\
\hline 15 & 180 & 11.43 \\
\hline 16 & 190 & 11.47 \\
\hline 17 & 200 & 11.52 \\
\hline 18 & 225 & 11.54 \\
\hline
\end{tabular}

Berdasarkan data dari Tabel 5.2, Perbandingan data PWM terhadadap tegangan dapat dilihat padagrafik dibawah ini:

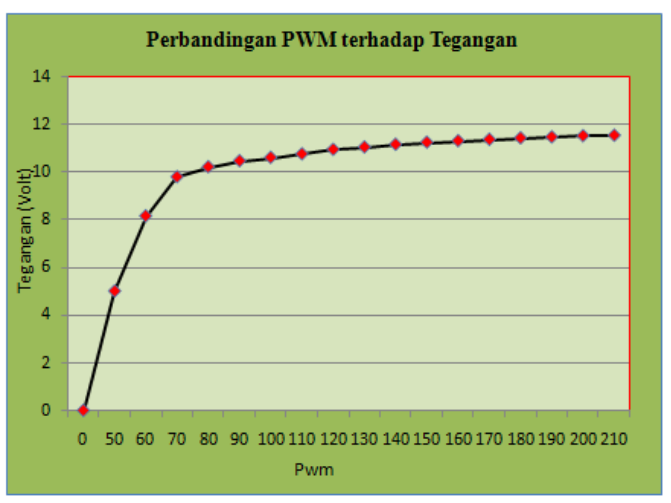

Data pengujian driver motor menunjukkan hasil bahwa pengaturan PWM melalui program berbanding lurus dengan output tegangan terukur pada driver motor, hal ini dapat dilihat pada gambar 4.4 grafik perbandingan PWM terhadap tegangan output driver motor, yaitu semakin besar nilai PWM yang diatur melalui program, semakin besar juga output tegangan terukur menggunakan multitester digital.

\subsubsection{Pengujian Dan Pengukuran Sinyal Output Xbee Transmitter}

Perencanaan

pengujian

transmitter dan receiver dilakukan untuk mengetahui apakah data yang dikirim berhasil atau tidak dan sesuai dengan instruksi yang telah dituliskan di program atau tidak, hasil dari kebenaran data yang diterima oleh mikro kontrol akan ditampilkan dalam bentuk serial monitor data pada software arduino.

Tabel 5.3 Pengujian Pengiriman data

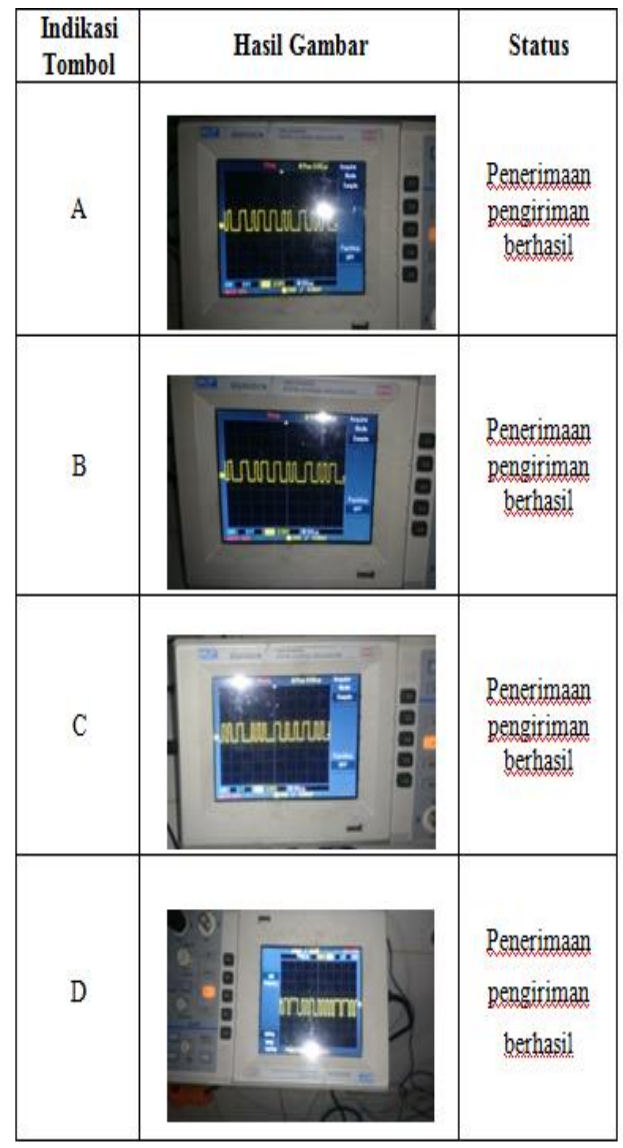

5.2.3 Pengujian Dan Pengukuran Sinyal Output Xbee Receiver Perencanaan pengujian transmitter dan receiver dilakukan 
untuk mengetahui apakah data yang dikirim berhasil atau tidak dan sesuai dengan instruksi yang telah dituliskan di program atau tidak, hasil dari kebenaran data yang diterima oleh mikro kontrol akan ditampilkan dalam bentuk serial monitor data pada software arduino.

Tabel 5.4 Pengujian Penerimaan data

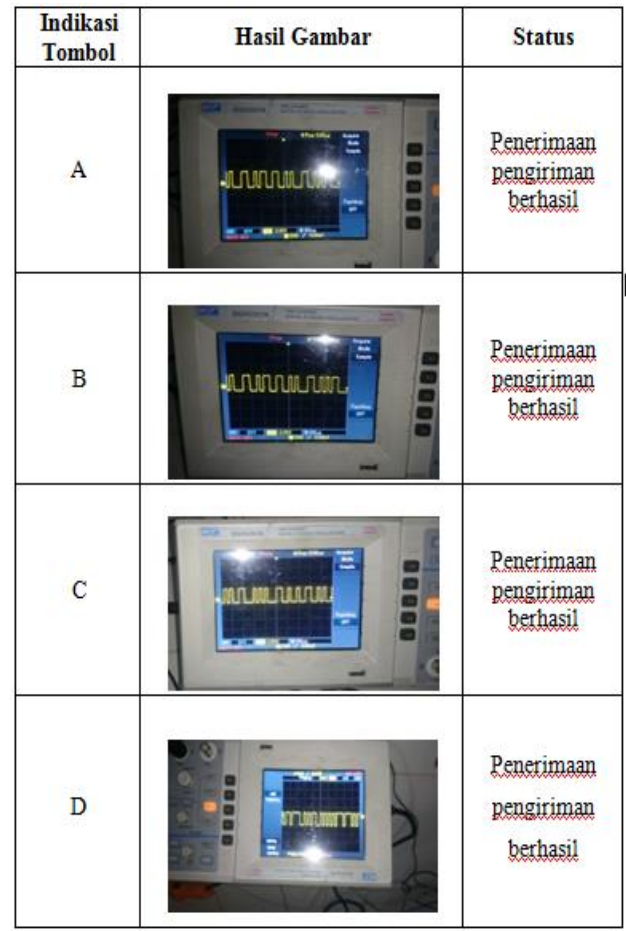

\subsubsection{Pengujian Respon Robot Terhadap Pengontrollan Menggunakan Remote \\ Perncanaan pengujian Respon}

Robot adalah untuk mengetahui apakah data yang telah berhasil diterima oleh penerima seterusnya diolah sebagai data pemberi instruksi berhasil sesuai dengan instruksi gerak aktuator atau motor.

Tabel 5.5 Pengujian Respon Motor Terhadap Remote kontrol

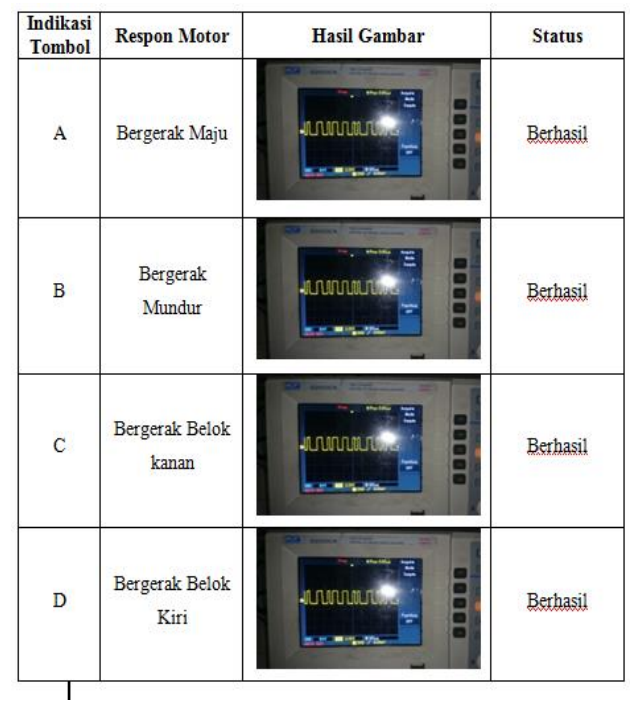

\subsubsection{Pengujian Jarak Kontrol Robot}

Pengujian jarak komunikasi bertujuan untuk mengetahui jarak kontrol wireless yang masih dapat digapai oleh robot.

Tabel 5.6 Pengujian 1 jarak kontrol robot

\begin{tabular}{|c|c|c|}
\hline No. & Jarak ( Meter) & Keterangan \\
\hline 1 & 10 & Ok \\
\hline 2 & 20 & Ok \\
\hline 3 & 30 & Ok \\
\hline 4 & 40 & Ok \\
\hline 5 & 50 & Ok \\
\hline 6 & 60 & Ok \\
\hline 7 & 70 & Ok \\
\hline 8 & 80 & Ok \\
\hline 9 & 90 & Ok \\
\hline 10 & 100 & gagal \\
\hline 11 & 101 & gagal \\
\hline 12 & 102 & gagd \\
\hline 13 & 103 & gagd \\
\hline 14 & 104 & gag \\
\hline 15 & 105 & gal \\
\hline
\end{tabular}

Tabel 5.7 Pengujian 2 jarak kontrol robot 


\begin{tabular}{|c|c|c|}
\hline No. & Jarak ( Meter) & Keterangan \\
\hline 1 & 10 & Ok \\
\hline 2 & 20 & pk \\
\hline 3 & 30 & $0 k$ \\
\hline 4 & 40 & $0 k$ \\
\hline 5 & 50 & $0 k$ \\
\hline 6 & 60 & $0 k$ \\
\hline 7 & 70 & Ok \\
\hline 8 & 80 & Ok \\
\hline 9 & 90 & gagal \\
\hline 10 & 100 & gagal \\
\hline 11 & 101 & gagal \\
\hline 12 & 102 & gagal \\
\hline 13 & 103 & gagal \\
\hline 14 & 104 & gagal \\
\hline 15 & 105 & gagal \\
\hline
\end{tabular}

Tabel 5.8 Pengujian 3 jarak kontrol robot

\begin{tabular}{|c|c|c|}
\hline No. & larak ( Meter) & Keterangan \\
\hline 1 & 10 & Ok \\
\hline 2 & 20 & Ok \\
\hline 3 & 30 & Ok \\
\hline 4 & 40 & Ok \\
\hline 5 & 50 & Ok \\
\hline 6 & 60 & Ok \\
\hline 7 & 70 & Ok \\
\hline 8 & 80 & gagal \\
\hline 9 & 90 & gagal \\
\hline 10 & 100 & gagad \\
\hline 11 & 101 & gagal \\
\hline 12 & 102 & gagal \\
\hline 13 & 103 & gagal \\
\hline 14 & 104 & gagal \\
\hline 15 & 105 & gagal \\
\hline
\end{tabular}

Berdasarkan hasil tabel diatas maka diketahui bahwa jangkauan jarak kontrol wireless dari komunikasi menggunakan xbee modul dalam range 90 meter dibanding dari hasil data sheet bahwa data ftersebut sesuai dengan spesifikasi dari module tersebut untuk itu dalam jangkauan 100 meter keatas penerimaan data adalah gagal, dari hasil tersebut

beberapa faktor diteliti bahwa range tersebut dapat dimaksimalkan apabila pengujian dilakukan dalam bentuk cuaca atau kondisi tertentu seperti di dalam ruangan, hal tersebut sangat mempengaruhi dari sistem komunikasi data menggunakan xbee modul.

\subsection{Kesimpulan}

Beberapa kesimpulan dapat diambil dari penelitian ini diantaranya sebagai berikut:

1. Perancangan mekanik robot wireless dirancang dengan bentuk robot beroda yang tiap roda di couple dengan motor dc dengan ukuran $5 \mathrm{~cm}$ x $7 \mathrm{~cm}$ menggunakan bahan acrilyc.

2. Perencanaan desain dan serta implementasi module xbee dan mikrokontrol telah berhasil di rancang , mikrokontrol mengunakan modul arduino tipe UNO dan wireless kontrol menggunakan xbee pro hasil implementasi sebagai berikut:

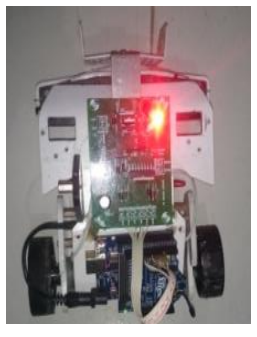

3. Pengaplikasian sistem kontrol menggunakan xbee wireless terhadap sistem gerak robot telah berhasil dilakukan dengan memanfaatkan metode kontrol yaitu serial wireless atau komunikasi tanpa kabel dengan format data pengiriman serial, keberhasilan sistem kendali 
tersebut ditandai dengan pemberian instruksi pada remote yang diterima dengan baik oleh robot dengan respon gerak seuai dengan perintah yang telah dituliskan pada program. Tingkat keberhasilan kontrol diuji berdasarkan indikasi jarak kontrol, dimana percobaan dilakukan sebanyak tiga kali dengan hasil jarak maksimum 90 meter pada ruangan tertutup.

\subsection{Saran}

Penelitian ini dinilai masih jauh dari kata sempurna, oleh karena itu diperlukan saran - saran untuk perbaikan kedepannya, yaitu sebagai berikut:

1. Adanya monitoring data yang secara langsung menghitung jarak terdeteksi sehingga dalam pengujian jarak jauh lebih mudah.

2. Mencari cara agar robot dapat diuji di semua kondisi sehingga hasil jauh lebih maksimal.

3. Mencoba varian modul komunikasi wireless dengan jarak komunikasi wireless yang lebih jauh.

\section{Daftar Pustaka}

1. Arduino Uno. (2011).diambil Juni 6, 2016, dari http://Arduino Uno.cc/.

2. Dimas Lazuardi Adya Putra., "Rancang Bangun Perangkat Keras Joystick PC Interaktif Untuk Aplikasi Permainan enis FPS(First Person Shooter) dengan mokrokontroler dan sistem komunikasi 802.15.4", PENSITS, Juli 2009.
3. Digi.2010."Xbee/Xbee-Pro ZB RF Modules". Digi International Inc: Minnetonka.

4. Kharisma, "Perancangan dan Pembuatan Perangkat Keras Untuk Pemantau Kondisi Hujan dengan Sistem Komunikasi 80215.4(Zigbee)", PENS-ITS, Juli 2009.

5. Nugraha, D.W., 2010. Perancangan Sistem Kontrol Robot Lengan yang Dihubungkan dengan Komputer. Majalah Ilmiah Mektek Tahun XII No. 3.

6. Slamet Hariyadi, "Sistem Koordinasi Robot Krci Expert Swarm 2008", Proyek akhir, Politeknik Elektronika Negeri Surabaya,ITS, September 2008.

7. Saleh, K., 2011. Rancang Bangun Robot Pemantau Wireless Berbasis Mikrokontroler ATMega8535 Menggunakan Bahasa Basic. Jurnal Penelitian Sains Vol. 14 No. 4(B).

8. X-CTU Configuration \& Test Utility Software. 